left patients who had used this product to their benefit for many years, and myself as a practitioner, no longer able to prescribe or recommend it, I was told that this was a matter of 'clinical judgement'.

I requested the name of their medical director so I could pursue this to be told that Squibb had a 'no names policy'; this also applied to the name of their chief executive, although presumably this has to be in the public domain.

To withdraw a medicine when no comparable alternative is available, not on grounds of safety nor efficacy, but solely for commercial reasons, seems to display a cavalier attitude to patient well-being and this from a company whose mission is 'to extend and enhance human life'. To do so behind a cloak of anonymity adds a further unacceptable dimension.

This example raises fundamental ethical principles relating to drug companies as to what is acceptable when commercial imperatives appear to outweigh the needs of patients.

In view of the implications perhaps the BDA could consider an approach to the Medicines and Healthcare products Regulatory Agency (MHRA) to clarify the issues involved.

G. Feaver

London

DOI: 10.1038/sj.bdj.2010.114

\section{INTERNET CAUTION}

Sir, I read with interest the article Dental patients' use of the Internet. ${ }^{1}$ I would like to reinforce the need for patients to be cautious about information available online by briefly discussing a condition called Neurocutaneous Syndrome, NCS, which I was recently made aware of.

NCS is described as 'a newly discovered toxicity disorder' and is 'characterized by neurological sensations, pain, depleted energy and memory loss as well as itchy cutaneous lesions'. The diagnostic criteria for NCS seem to consist of only two aspects. One, that the patient has NCS symptoms and two, that one or more teeth are restored with a 'toxic' material.

Online $^{2}$ there is a large amount of information including eight published articles (62 pages). There are significant claims, related to NCS, such as:
- 'Oral symptoms especially gum disease, occur nearest the damage area and should not be surprising. They are caused by either toxic dental materials or by secondary bacterial infections.'

- 'This epidemic-in-disguise has been routinely misdiagnosed by medical professionals who often label patients as delusional.'

- Over 400 dental products are listed as 'causative agents' and 'are now recognised as toxic'. The list of 'toxic' products reads almost as an inventory for a dental surgery. Examples include Dycal, Life, Sealapex, Prime and Bond, Temp bond, Zinc oxide products, light cured dental composites, gutta percha, prophy paste and Aquasil to name but a few.

NCS as a condition is not evidencebased medicine. The evidence so far presented has been of poor quality with several discrepancies. The highest levels of evidence presented are case studies and opinions, which are the weakest levels of evidence, ${ }^{3}$ level 3 and 4. All the publications are produced by a single author. Furthermore all but one are published in the same non-dental journal, with the only one in a dental journal, triggering a flood of critical letters. ${ }^{4}$

The case studies have numerous discrepancies, for example, the first case study in the most recent publication describes NCS symptoms in a patient. The author diagnoses NCS on the basis that she had dental work completed in 1982, 20 years before any symptoms developed. However 'blood biocompatibility test results are not available to date' and the author lost contact with the patient before dental rehabilitation was started. It seems that all the author has done is to describe a case where a patient with a dermatological complaint had fillings.

From the information available I can understand why a patient would be concerned about this condition, and present to their dentist requesting removal of their fillings.

Biocompatibility issues are a recognised complication and can produce systemic presentations ${ }^{5}$ but I feel the claims of the existence of this condition and the proposed treatment of dental rehabilitation by removing all fillings is not justified given the current lack of a significant evidence base.

R. Holliday Edinburgh

1. Ní Riordáin R, McCreary C. Dental patients' use of the Internet. Br Dent J 2009; 207: 583-586.

2. Parasitology Center Inc. http://www.parasitetesting.com/

3. Scottish Intercollegiate Guidelines Network (SIGN). SIGN 50, a guideline developer's handbook. 2008.

4. Readers sound off (letters). CDA J 2004; 32: 956. http://www.cda.org/page/Library/cda_member/ pubs/journal/jour1204/feedback.pdf

5. van Noort R. Introduction to dental materials, 2nd ed. Mosby, 2002.

DOI: $10.1038 /$ sj.bdj.2010.115

\section{THE NHS REALITY}

Sir, in relation to your editorial No going back (BDJ 2009; 208: 45), the NHS was dreamt of as being free at the point of delivery and yet over time patient charges have been steadily increasing. Patients now pay a much bigger share of dental fees and this is not NHS dentistry other than in the imagination of Department of Health (DoH). In reality it is actually a very cheap form of private dentistry forced upon the profession by dictatorial bullying. Perhaps I am unduly harsh but I believe that if the politicians were actually interested in the nation's dental wellbeing, they should have purchased essential treatment at reasonable prices. Good quality examination and treatment planning leads its way to appropriate treatment. Most dental professionals would be solidly behind such an honest service.

I see new graduates coming in for job interviews and their first question usually is to enquire about the potential for private practice. The DoH can bring in as many figures as they wish but the reality is as you write 'no going back'. There is a trend away from NHS dentistry which seems to be developing momentum slowly and quietly. I congratulate you for noting this in the way that you have.

I. A. S. Syed By email

DOI: $10.1038 /$ sj.bdj.2010.116 